\title{
THE ACCURACY OF THE PHOTOELECTRIC EARPIECE TECHNIQUE IN THE MEASUREMENT OF CARDIAC OUTPUT
}

\author{
BY \\ MICHAEL THOMAS,* RAOUL MALMCRONA $\dagger$, AND JOHN SHILLINGFORD \\ From the Medical Research Council Cardiovascular Research Group, Department of Medicine, Postgraduate Medical \\ School of London
}

Reiceived March 8, 1965

In 1897 Stewart described the indicator dilution method for the measurement of cardiac output, and following the work of Hamilton and his associates $(1928 \mathrm{a}, \mathrm{b} ; 1932)$ in man, the validity of the principles underlying the method has become established. Numerous papers have described the correlation between results obtained by this and the Fick techniques (Hamilton et al., 1948; Werkö et al., 1949; Friedlich, Heimbecker, and Bing, 1950; Nicholson and Wood, 1950, 1951; Kopelman and Lee, 1951 ; Eliasch, 1952; Shadle et al., 1953; Doyle et al., 1953; Shepherd, Bowers, and Wood, 1955; Neely et al., 1954; Taylor and Shillingford, 1959; Phinney et al., 1963).

The usual methods for obtaining dye dilution curves involve the use of arterial puncture and a continuous withdrawal cuvette densitometer. Following the work of Wood and Geraci (1949) the photoelectric earpiece was used for drawing dye dilution curves and the use of these for estimation of cardiac output was later reported (Nicholson and Wood, 1950, 1951; Knutson et al., 1950; Milnor et al., 1953; Gilmore et al., 1954; Taylor and Shillingford, 1959; McGregor, Sekelj, and Adam, 1961 ; Phinney et al., 1963). The method has been accepted with some reserve, however, owing to the difficulties of recording and calibrating the curves (Beard, Nicholson, and Wood, 1950; Beard and Wood, 1951). With the improvement of high gain electronic amplifiers and modifications to the technique, these difficulties have now been largely overcome.

In a previous paper (Gabe, Tuckman, and Shillingford, 1962) from this laboratory, a method for the determination of relative changes in cardiac output from non-calibrated earpiece dye dilution curves was described. The purpose of this paper is first to describe the method for measuring absolute cardiac output from calibrated earpiece dilution curves, assessing critically each step in the technique, and secondly to compare results with those obtained from simultaneous intermittent arterial sampling. This method offers particular advantage in measuring cardiac output at frequent intervals when multiple arterial puncture may be avoided.

\section{MeTHODS}

Photoelectric Earpiece. The selenium photoelectric earpiece and recording amplifier made by the Cambridge Instrument Co., with minor modifications to improve stability, were used. The input circuit modification made is shown in Fig. 1. The characteristics of this apparatus have been reported in detail (Gabe and Shillingford, 1961).

* Medical Research Council Clinical Research Fellow.

$\dagger$ In receipt of grants from the Swedish National Association against Heart and Lung Diseases and from the Wellcome Research Foundation. Present address: Medical Department 1, Sahlgrenska Sjukhuset, University of Gothenburg, Sweden. 
ORIGINAL CIRCUIT

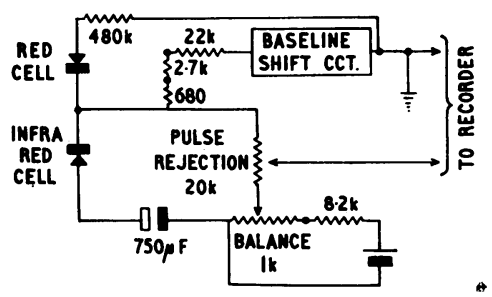

MODIFIED CIRCUIT

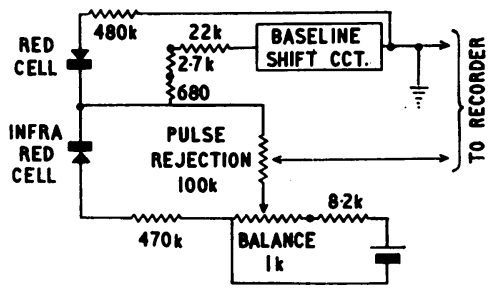

Fig. 1.-Original circuit: modified circuit.

Coomassie Blue (I.C.I.) (Taylor and Thorpe, 1959; Taylor and Shillingford, 1959) was used as indicator in doses up to $100 \mathrm{mg}$. per injection. Injections were made from a silicone greased syringe capable of delivering four equal doses of dye without refilling. The syringe is described elsewhere (Gabe and Shillingford, 1961). Calculation of the amount of dye injected was made following the procedure on the patient. The catheter used was washed with water and then with acetone. After drying by passing warm air through the lumen, water was injected from the calibrated syringe through the dried catheter into a weighed container. Re-weighing gave the volume of dye injected into the patient.

The recording apparatus was switched on at least one hour before use and the whole earpiece was warmed to $37^{\circ} \mathrm{C}$. in a small electric heating box in the apparatus. A vasodilator cream (Trafuril, I.C.I.) was applied to the pinna five minutes before placing the warmed earpiece in position. The earpiece was adjusted so that each side touched the surface of the ear and it was held securely in position with adhesive tape. The cable was also fixed to the forehead with adhesive tape. At least ten more minutes are required to complete thermal equilibrium. While in use on the patient the earpiece was covered with a black cloth to exclude light. When the instrument was able to draw a steady baseline over three minutes, it was regarded as ready for use. Time was saved by attending to the earpiece at an early stage in an investigation. The dye was injected through a fine polythene catheter* $(0.030$ in. internal diameter) about $25 \mathrm{in} .(63.5 \mathrm{~cm}$.) in length inserted into the median basilic vein through an intravenous infusion needle. The tip was advanced so that the distal end lay in the region of the superior vena cava. Before injection, $10 \mathrm{ml}$. of blood were taken into a heparinized tube to provide plasma for blanks and standards.

After inscription of the curve, the dye within the catheter was aspirated together with 5-10 ml. of blood. The catheter was then severed close to the needle point and a new dye-free needle and saline-loaded syringe introduced into the cut end. $5 \mathrm{ml}$. of saline were slowly injected. At approximately 3 minutes after the dye injection, the catheter was cleared of saline by aspiration and a 5-ml. sample of blood was taken; the sampling period was marked on the tailpiece.

Extraction of Dye. Plasma was separated and blanks and standards were prepared from venous blood taken via the catheter before any dye was injected.

Into 4 tubes were pipetted respectively (1) $1 \mathrm{ml}$. (2) $0.9 \mathrm{ml}$. (3) $0.8 \mathrm{ml}$. of control plasma, and (4) $1 \mathrm{ml}$. of the calibration sample. To tubes (2) and (3) were added 0.1 and $0.2 \mathrm{ml}$. of a standard Coomassie Blue prepared from the batch in current use. This had been diluted with distilled water to $1 / 200$ such that the resultant concentration in plasma was approximately $10 \mathrm{mg}$./1. in tube (2) and $20 \mathrm{mg}$./1. in tube (3). To each of the 4 tubes were then added $2 \mathrm{ml}$. of saturated urea. This was followed by $4 \mathrm{ml}$. of acetone. The precipitate was then gently dispersed by shaking and the tubes allowed to stand for at least 2 hours. Two further additions were then made: (1) $0.5 \mathrm{ml}$. of approximately 10 per cent zinc sulphate and (2) $0.5 \mathrm{ml}$. of $0.5 \mathrm{~N}$ sodium hydroxide. The exact normality of these two solutions is not important but it is vital that they are chemically equivalent. They were titrated against each other using phenolphthalein as an indicator. Appropriate dilution with distilled water was necessary from time to time when stocks were kept for long periods. Likewise stock zinc sulphate occasionally required filtration and retitration. All reagents were "analytical grade". After addition of zinc sulphate and sodium hydroxide a further one-hour period of standing allowed a flocculate to form.

Ten minutes of centrifuging at about 3000 r.p.m., removing the supernatant by Pasteur pipette, and recentrifuging, resulted in a crystal clear solution. The final extracted solutions were stored in the dark at room temperature for reading at a convenient time. They were securely stoppered to prevent evaporation.

* Intramedic (U.S.A.) PE 60. 
The optical density of final solutions was measured by spectrophotometry (Unicam Spectrophotometer) at a wavelength of $585 \mathrm{~m} \mu$.

From the optical densities of the standards and the calibration sample, the dye concentration in the blood three minutes after injection was calculated.

Hamatocrit. Hæmatocrit was measured by centrifuging blood in a Wintrobe tube at 3000 r.p.m. for 30 minutes. The radius to the tip of the tube was $15 \mathrm{~cm}$. An allowance of 2 per cent was made for trapped plasma.

Calculation of Cardiac Output. The area under the curve was calculated by summing the height of the curve from the baseline at one-second intervals. The downslope was extrapolated on semilogarithmic paper to two decades. Tailpiece height was measured from the same baseline. The cardiac output was calculated from the following formula.

$$
\text { C.O. }=\frac{\text { Dye injected }(\mathrm{mg} .) \times 60}{\frac{\text { Area of curve }(\mathrm{mm} . \mathrm{sec} .)}{\text { Tail height }(\mathrm{mm} .)} \times \text { Plasma dye concentration }(\mathrm{mg} . / 1 .)} \times \frac{100}{100-\text { hæmatocrit per cent }}
$$

Intermittent Arterial Sampling. As a reference method the cardiac output was calculated from a dye dilution curve obtained by direct arterial sampling using ${ }^{131} \mathrm{I}$ human serum albumin as indicator.

The fraction cutter consists of 205 -ml. syringes mounted on a stainless steel plate which revolves at a known speed. As each syringe comes into position opposite the catheter* an automatic arm withdraws the plunger of the syringe. After collection of blood sample they are injected manually from the syringes into previously weighed plastic pots which are then re-weighed. Small variations in volume are corrected by weighing. In six cases arterial blood samples were collected by free flow using an alternative disc mounted above the main turn-table. This allowed direct collection of blood into the weighed plastic pots. The specific gravity of blood was taken into account by weight correction of 6 per cent.

$30 \mu \mathrm{c}$ of radioactive iodinated human serum albumin $\left({ }^{131} \mathrm{I}\right)$ were mixed with $20 \mathrm{ml}$. of 2 per cent Coomassie Blue. Using the calibrated syringe, $5 \mathrm{ml}$. of this mixture were injected into the great veins through a polythene catheter and simultaneous indicator dilution curves recorded by the earpiece and by direct arterial sampling. The radioactivity in each blood sample was estimated and the indicator dilution curve drawn. Measurement of radioactivity injected was made in two ways. $5 \mathrm{ml}$. of the mixture was injected in the same way into distilled water containing some of the patient's plasma and made up to 1 litre. The radioactivity in a weighed sample of this was estimated. In addition a small quantity of the undiluted mixture was injected into a weighed plastic pot and counted directly. The error due to different geometry within the counting chamber was small and was ignored. The volume of injected mixture was determined as described. The results shown are based on the diluted standard. From the total radioactivity injected and the ${ }^{131}$ I dilution curve the cardiac output was calculated by the Hamilton method.

\section{RESULTS}

Injection of Dye. Repeated measurement (10 times) of the amount of dye delivered from the syringe, using the calibration method described, showed a maximum difference of less than 0.5 per cent.

Stability of Photoelectric Earpiece and Recording System. After the earpiece and recording system were set up for cardiac output determination, the stability was tested by observing baseline drift. No drift was detectable over three minutes when the patient was breathing oxygen. The gain was such that subsequent injection of $50 \mathrm{mg}$. of dye produced a one-half to three-quarter scale deflection at the peak of the curve.

Linearity of Apparatus. The response of the apparatus to different concentrations of dye in water within a $3 \mathrm{~mm}$. glass cuvette placed between the light source and photocells of the earpiece was tested. The response was linear at both low and high concentrations (Fig. 2A and B). Evidence of linearity of the system as used was obtained by giving five successive injections of $50 \mathrm{mg}$. Coomassie Blue at 3-minute intervals to a normal subject resting quietly. If the apparatus is linear and there is no change in ear thickness, the area of paper beneath the dye curve, excluding the effects of recirculation by extrapolation, should be inversely proportional to the cardiac output. As the sub-

\footnotetext{
* Intramedic (U.S.A.) PE 160.
} 


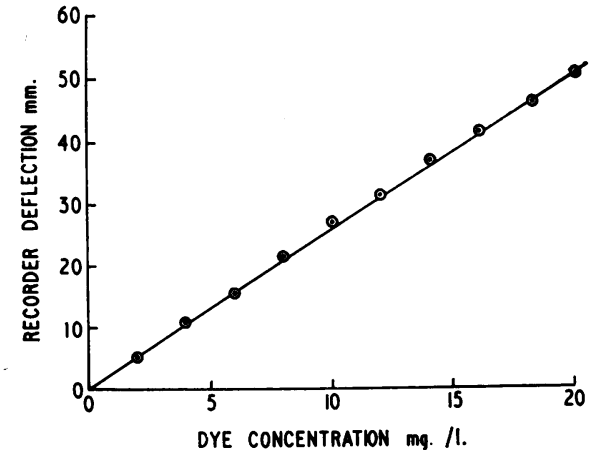

A

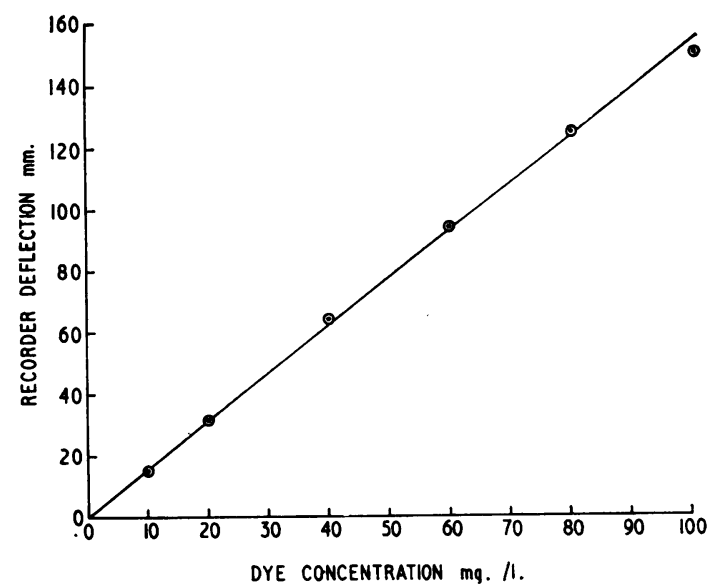

B

FIG. 2.-The relation between the galvanometer response and the concentration of dye in water within a $3 \mathrm{~mm}$. optical cuvette. (A) Low concentration; (B) high concentration.

ject was resting quietly during the experiment we should expect little evidence of any change in the cardiac output. On the other hand, a steady change in the calculated output from the curves would suggest alinearity in the apparatus. Fig. 3 shows a series of 5 curves from one subject, with the calculated area below each. No alinearity is apparent.

Linearity was further tested by giving serial standard injections of dye at 4-minute intervals while allowing the recorder to run continuously without baseline adjustments. A blood sample was taken from an indwelling brachial arterial needle 3 minutes after each injection. The dye was extracted from the plasma and its concentration determined. The tail height at each sampling time was measured and the ratio of plasma dye concentration to tailpiece height calculated. Fig. 4 illustrates the relation between tail height and plasma dye concentration after consecutive dye injections made on two occasions in different patients. The data given in Table I show the consistency of tailpiece calibration obtained.

In view of the long time involved in this experiment many of the possible errors are potentially much greater than they would be normally. Particularly apparent is the good baseline stability over a period many times longer than is necessary when making isolated determinations.

Dye Extraction. To test the reproducibility of dye extraction and the procedure involved in estimating the dye concentration, 10 plasma dye standards of approximately $10 \mathrm{mg} . / 1$. were prepared with plasma from one patient and 10 plasma dye standards of approximately $20 \mathrm{mg}$. $/ 1$. were prepared 
TABLE I

\begin{tabular}{c|c|c|c|c}
\hline Patient & $\begin{array}{c}\text { Tail } \\
\text { height } \\
\text { (mm.) }\end{array}$ & $\begin{array}{c}\text { Dye } \\
\text { concentration } \\
\text { (mg./1.) }\end{array}$ & D/T* & $\begin{array}{c}\text { Per cent } \\
\text { deviation } \\
\text { from mean }\end{array}$ \\
\hline J. E. & 16.2 & 19.9 & 1.228 & -1.9 \\
& 29.5 & 36.4 & 1.233 & -1.5 \\
& 40.5 & 53.1 & 1.311 & +4.7 \\
\hline T. G. & 51.0 & 63.0 & 1.235 & $-1 \cdot 4$ \\
\hline & 15.0 & 15.0 & 1.000 & -3.3 \\
& 28.0 & 16.4 & 1.006 & +4 \\
\hline
\end{tabular}

* D/T $=\frac{\text { Dye concentration }}{\text { tail height. }}$

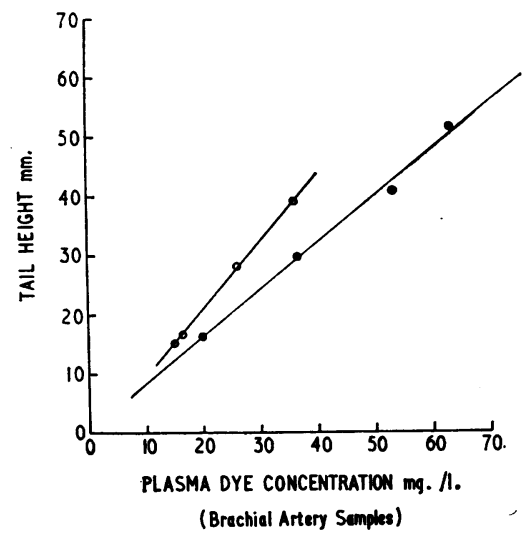

FIG. 4.-Serial injections of $50 \mathrm{mg}$. Coomassie Blue given to two normal resting subjects. No baseline adjustments were made. The linear relation between arterial plasma dye concentration and tailpiece height is shown.
TABLE II

Optical Density of Plasma Dye Standards (Two Series made from two Different Plasma Samples)

\begin{tabular}{l|c}
\hline \multicolumn{2}{c}{ Spectrophotometer readings } \\
\hline $20 \mathrm{mg} . / 1$. & $10 \mathrm{mg} . / 1$. \\
\hline 0.171 & 0.083 \\
0.172 & 0.083 \\
0.171 & 0.083 \\
0.174 & 0.084 \\
0.178 & 0.084 \\
0.174 & 0.083 \\
0.173 & 0.082 \\
0.178 & 0.083 \\
0.174 & 0.084 \\
0.173 & 0.083 \\
\hline
\end{tabular}

from plasma from another patient. The routine procedure for estimating dye concentrations was undertaken. The maximum difference in spectrophotometric readings found in those two series was 4 per cent. The figures are given in Table II.

Central Venous and Arterial Dye Concentration. Comparisons of dye concentration in central venous with synchronous brachial artery calibration samples were made. The comparison of dye concentration in the paired samples, taken three minutes after injection, is shown in Fig. 5. Each point represents a separate procedure. The quantity of dye injected was not constant. In assessing the relation, the small error in dye extraction should be borne in mind. The continuous line represents the line of identity: a close agreement is seen.

Venous and Arterial Hamatocrit. Comparison of the hæmatocrit of central venous blood samples withdrawn through the catheter was made with the haematocrit of arterial blood samples. The relation is shown in Fig. 6.

Comparison of the Measurement of Cardiac Output by the Photoelectric Earpiece and Direct Arterial Sampling Methods. The cardiac outputs obtained by the earpiece method using central venous blood sampling were compared with those obtained by simultaneous arterial sampling by a fraction cutter. Fifteen patients were investigated. Within a range of cardiac output measured (3-9 1./min.) there was a close agreement between the cardiac outputs obtained from the two methods (Fig. 7). Only three of the results obtained by the earpiece method fell outside \pm 10 per cent of the 


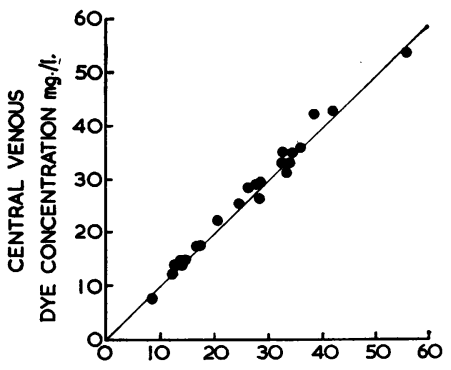

ARTERIAL DYE CONCENTRATION mg/l.

FIG. 5.

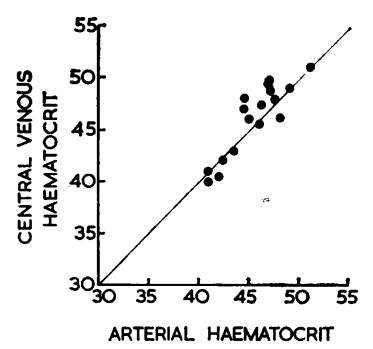

FIG. 6.

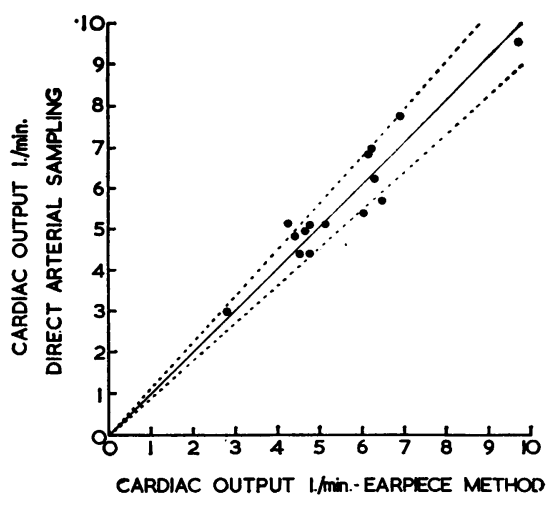

FIG. 7.

FIG. 5.-A comparison of central venous dye concentration with synchronous brachial arterial dye concentration 3 minutes after injection.

FiG. 6.-A comparison of arterial and central venous hæmatocrit.

FIG. 7.-Comparison of the results of measuring cardiac output by the photoelectric earpiece technique and direct arterial sampling methods. The continuous line represents the line of identity. Interrupted lines represent \pm 10 per cent values.

cardiac output obtained by the direct arterial method. The correlation coefficient of results obtained by the earpiece method to those obtained by direct arterial sampling was 0.94 .

\section{Discussion}

The vascular system of the ear provides a natural cuvette in that there is a flat and relatively thin vascular bed that can easily be transilluminated. Vasodilatation or constriction would, however, alter the characteristics of the vascular bed. Previous work (Gabe et al., 1962) was directed towards this problem and direct comparison of the earpiece curves against simultaneous arterial curves showed a close agreement even after the administration of noradrenaline, hypotensive agents, and changes in posture. It is of course important that the earpiece should not move at any time during the procedure or between successive measurements. Likewise thermal and electrical stability should be achieved before beginning an investigation.

If the photoelectric earpiece is to be used for quantitative work, it is desirable that there should be a linear relation between electrical output and concentration of dye in the blood. It is known that the linearity of the relation between light intensity and current from a selenium barrier layer photoelectric cell is greatly dependent on the value of resistance in series with the cell. In accordance with Beer's law of optical absorption, an exponential relation exists between light transmission and the concentration of the dye solution. The curvilinearity must be corrected for in calculation of the curves. Alternatively, a correction may be introduced into the amplifier circuit to allow for this. It was found possible (Gabe and Shillingford, 1961) to achieve the necessary correction by feeding the barrier layer photocell into a high resistance; the relation between the current output and light intensity was then alinear and the current output becomes more proportional to the logarithm of light intensity. This alinearity tends to oppose the alinearity implicit in Beer's law. This property has been used in oximetry to produce an instrument that records oxygen saturation linearly (Goldie, 1942; Paul, 1953). Experimentally it was found that the alinearities can be empirically opposed to produce near linearity between current output and concentration of dye over a wide range (Gabe and Shillingford, 1961).

A practical assessment of the use of the photoelectric earpiece for quantitative work must be made. The linearity of the earpiece to concentrations of dye in the ear is of fundamental importance in relation to the accuracy of the method. This linearity must be maintained at low levels of dye concentration in relation to the measurement of the height of the tail and in high concentration for 
the correct inscription of the higher parts of the curve. Linearity at high concentrations is particularly required for multiple curves where the background of indicator is continuously increasing.

The method also relies on the blood sample used for calibrating the curve being representative of the blood perfusing the ear at the time the tailpiece is being inscribed. We have assumed that the blood perfusing the ear when a vasodilator cream has been used is arterial. Comparison has, therefore, been made between the dye concentration and the hæmatocrit of arterial blood and central venous blood used for calibration.

The use of the catheter is important from many points of view. If the dye is injected into a peripheral vein there is a risk of some of it being sequestered in the venous system, especially in the presence of venous spasm. Peripheral venous sampling from the antecubital vein may lead to inaccuracies when mixing in the superficial veins of the forearm is incomplete. Because of this the blood sample used for calibration of the dye curve is withdrawn through the catheter with the tip placed in the great veins. Here the dye concentration closely corresponds to that in the brachial artery at the usual sampling time, three minutes after injection of dye. Great care has to be taken when sampling through the catheter which has been used for injection that the sample is not contaminated by residual dye left on the catheter needle. For this reason we cut off the injection needle, replace it by a new needle, and rinse thoroughly before sampling.

The average time for injection of $2 \mathrm{ml}$. of dye from a calibrated syringe through this tube is 2 seconds. This is well inside the half appearance time as recorded at the ear in the average adult. In model experiments it has been shown that prolongation of the injection up to half the appearance time of the dye does not greatly distort the curve (Hoffman and Shillingford, 1957).

Analysis of the steps involved in the measurement of cardiac output by the photoelectric earpiece technique is important for refining the practical details. It also provides some opportunity for assessing the accuracy with which the curve may be calibrated. Furthermore it enables one to exclude the possibility of different errors that may cancel out each other in the final result. However, the final assessment of the reliability of the method to measure cardiac output lies in comparison with a direct method for sampling the indicator dilution curve. Ideally comparison of methods should be simultaneous. In this work the same indicator dilution curve was recorded and calibrated by the two methods. The final comparison involves errors inherent in the several steps of both methods.

\section{SUMMARY}

The measurement of the cardiac output by the photoelectric earpiece technique has been evaluated. The accuracy of the dye dilution curve calibration from the concentration of dye in the blood, obtained by dye extraction, and the height of the tail of the curve has been assessed. Comparison between the result of measuring the cardiac output by direct intermittent arterial sampling using ${ }^{131} \mathrm{I}$ as indicator and simultaneous measurement from the dye curve recorded by the photoelectric earpiece has shown good agreement. By this method cardiac output can be measured without arterial puncture.

The authors wish to thank Mr. Norman Levy and the Postgraduate Medical School workshop for the construction of the intermittent arterial blood sampler.

They are also indebted to Mr. Peter Burgess and Miss Diana Cuttriss for technical assistance. Miss Jean Powell drew the diagrams.

\section{REFERENCES}

Beard, E. F., Nicholson, J. W., and Wood, E. H. (1950). Application of an ear oximeter to estimation of cardiac output by the dye method in man. J. Lab. clin. Med., 36, 798.

- , and Wood, E. H. (1951). Estimation of cardiac output by the dye dilution method with an ear oximeter.J.appl. Physiol., 4, 177.

Doyle, J. T., Wilson, J. S., Lépine, C., and Warren, J. V. (1953). An evaluation of the measurement of the dyedilution method by the cardiac output and of the so-called pulmonary blood volume. J. Lab. clin. Med., $41,29$.

Eliasch, H. (1952). The pulmonary circulation at rest and on effort in mitral stenosis. Scand. J. clin. Lab. Invest., 4, Suppl. 4. 
Friedlich, A., Heimbecker, R., and Bing, R. J. (1950). A device for continuous recording of concentration of Evans blue dye in whole blood and its application to determination of cardiac output. J. appl. Physiol., 3, 12.

Gabe, I., and Shillingford, J. (1961). The photoelectric earpiece technique for recording dye dilution curves. Brit. Heart J., 23, 271.

—, Tuckman, J., and Shillingford, J. P. (1962). Determination of relative changes in cardiac output from noncalibrated earpiece dye-dilution curves. Circulat. Res., 11, 405.

Gilmore, H. R., Hamilton, M., Kopelman, H., and Sommer, L. S. (1954). The ear oximeter: its use clinically and in the determination of cardiac output. Brit. Heart J., 16, 301.

Goldie, E. A. G. (1942). A device for the continuous indication of oxygen saturation of circulating blood in man. J. sci. Instrum., 19, 23.

Hamilton, W. F., Moore, J. W., Kinsman, J. M., and Spurling, R. G. (1928a). Simultaneous determination of the pulmonary and systemic circulation times in man and of a figure related to the cardiac output. Amer.J.Physiol., 84, 338.

$-, \frac{1}{\text { and }},-$ and $(1928 \mathrm{~b})$. Simultaneous determination of the greater and lesser circulation times, of the mean velocity of blood flow through the heart and lungs, of the cardiac output and an approximation of the amount of blood actively circulating in the heart and lungs (Abstracted). Amer. J. Physiol., 85, 377.

$-, \frac{1}{-}, \frac{1}{-}$ and - (1932). Studies on the circulation. IV. Further analysis of the injection method, and of changes in hemodynamics under physiological and pathological conditions. Amer. J. Physiol., 99, 534.

-, Riley, R. L. Attyah, A. M., Cournand, A., Fowell, D. M., Himmelstein, A., Noble, R. P., Remington, J. W., Richards, D. W., Jr., Wheeler, N. C., and Witham, A. C. (1948). Comparison of the Fick and dye injection methods of measuring the cardiac output in man. Amer. J. Physiol., 153, 309.

Hoffman, J. I. E., and Shillingford, J. P. (1957). Minor factors influencing indicator dilution curves. Clin. Sci., 16, 1.

Knutson, J. R. B., Taylor, B. E., Ellis, E. J., and Wood, E. H. (1950). Studies on circulation time with the aid of the oximeter. Proc. Mayo Clin., 25, 405.

Kopelman, H., and Lee, G. de J. (1951). The intrathoracic blood volume in mitral stenosis and left ventricular failure. Clin. Sci., 10, 383.

McGregor, W., Sekelj, P., and Adam, W. (1961). Measurement of cardiac output in man by dye dilution curves using simultaneous ear oximeter and whole blood cuvette techniques. Circulat. Res., 9, 1083.

Milnor, W. R., Talbot, S. A., McKeever, W. P., Marye, R. B., and Newman, E. V. (1953). A photoelectric ear densitometer for continuously recording the arterial concentration of T-1824 in the dye-dilution method. Circulat. Res., $1,117$.

Neely, W. A., Wilson, F. C., Jr., Milnor, J. P., Hardy, J. D., and Wilson, H. (1954). Cardiac output: A clinical comparison of the direct Fick, dye, and ballistocardiographic methods. Surgery, 35, 22.

Nicholson, J. W., III, and Wood, E. H. (1950). Estimation of cardiac output and blood volume by continuous recording of Evans blue time-concentration curves in man, employing an oximeter (Abstracted). Amer. J. Physiol., 163, 738.

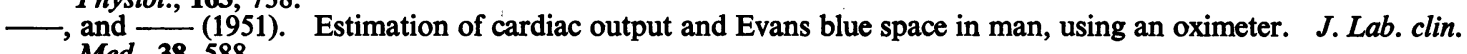
Med., 38, 588.

Paul, W. (1953). An oximeter for continuous absolute estimation of oxygen saturation. J. sci. Instrum., $30,165$.

Phinney, A. O., Clason, W. P. C., Stoughton, P. V., and McLean, C. E. (1963). Measurement of cardiac output using the photoelectric earpiece: a comparison with simultaneous Fick measurements. Circulat. Res., 13, 80.

Shadle, O. W., Ferguson, T. B., Gregg, D. E., and Gilford, S. R. (1953). Evaluation of a new cuvette densitometer for determination of cardiac output. Circulat. Res., 1, 200.

Shepherd, J. T., Bowers, D., and Wood, E. H. (1955). Measurement of cardiac output in man by injection of dye at a constant rate into the right ventricle or pulmonary artery. J. appl. Physiol., 7, 629.

Stewart, G. N. (1897). Researches on the circulation time and on the influences which affect it: IV. The output of the heart. J. Physiol. (Lond.), 22, 159.

Taylor, S. H., and Shillingford, J. P. (1959). Clinical applications of Coomassie blue. Brit. Heart J., $21,497$.

, and Thorpe, J. M. (1959), Properties and biological behaviour of Coomassie blue. Brit. Heart J., $21,492$.

Werkö, L., Lagerlöf, H., Bucht, H., Wehle, B., and Holmgren, A. (1949). Comparison of the Fick and Hamilton methods for the determination of cardiac output in man. Scand. J. Clin. lab. Invest., 1, 109.

Wood, E. H., and Geraci, J. E. (1949). Photoelectric determination of arterial oxygen saturation in man. J. Lab. clin. Med., 34, 387. 